\title{
ANÁLISE INTEGRADA DO MEIO FíSICO COMO SUBSÍDIO AO DIAGNÓSTICO DE PROCESSOS EROSIVOS NA BACIA DO RIBEIRÃO EXTREMA EM ANÁPOLIS (GO)
}

\author{
INTEGRATED ANALYSIS MIDDLE PHYSICAL LIKE SUBSIDY FOR THE DIAGNOSTIC OF \\ PROCESSES EROSIVE ON BASIN OF THE EXTREMA LARGE CREEK IN ANÁPOLIS (GO)
}

ANÁLISIS INTEGRADO DEL MEDIO FISICO CÓMO SUBSIDIO DEL DIAGNÓSTICO DEL
PROCESO EROSIVO EN LA CUENCA DEL RIBEIRAO EXTREMA EN ANÁPOLIS (GO)

Leide Laura F. M. Teixeira - UFG - Goiânia - Brasil

leidelaurateixeira@yahoo.com.br

Patrícia de Araújo Romão - UFG - Goiânia - Brasil

pat_iesa@yahoo.com.br

\begin{abstract}
Resumo
Atualmente, em escala variável, as cidades brasileiras apresentam problemas comuns, derivados das intensas modificações sofridas em décadas anteriores e agravados ao longo dos anos, pela falta de planejamento e controle da utilização da terra. Na cidade de Anápolis-GO, o uso das terras, não levou em consideração as fragilidades do meio físico em que se inseria, condicionando ao município problemas de ordem ambiental, que se refletem na ocorrência de processos erosivos lineares, assoreamentos e inundações. A bacia do ribeirão Extrema é uma das áreas de Anápolis com esse tipo de problema ambiental. Diante disso, o presente trabalho investigou a relação entre os condicionantes do meio físico, incluindo a sua utilização e a ocorrência de processos erosivos lineares nessa bacia hidrográfica. Fundamenta-se na análise integrada dos componentes da natureza e da sociedade, viabilizada com 0 auxílio das tecnologias de geoprocessamento. 0s resultados obtidos mostram que a distribuição dos focos erosivos está associada tanto aos condicionantes naturais quanto antrópicos. As erosões localizam-se, principalmente, sobre formas de relevo com declividade maior que $10 \%$, recobertos por latossolos e cambissolos, desenvolvidos a partir de rochas do complexo Granulítico Anápolis-Itauçu e do Grupo Araxá Sul de Goiás, onde o uso da terra não conta com infraestruturas adequadas.
\end{abstract}

Palavras-chave: Análise integrada. Meio físico. Uso da terra. Erosão.

\begin{abstract}
Currently, in changeable scale, the Brazilian cities present common problems, derivatives of the intense modifications suffered in previous and aggravated decades throughout the years, for the lack of planning and control of the use of the land. In the city of Anápolis-GO, the use of lands, did not take in consideration the fragilities of the environment where if it inserted, conditioning the city problems of environmental order, that if they reflect in the occurrence of linear erosive processes, silting and floodings. The basin of Extrema large creek is one of the areas of Anápolis with this type of environmental problem. Ahead of this, the present work investigated the relation between the constraints of the environment, including its use and the occurrence of linear erosive processes in this hydrographic basin. It is based on the integrated analysis of the components of the nature and the society, made possible with the aid of the geoprocessing technologies. The results obtained show that the distribution of the erosive focus is associated in such a way with both to natural conditions as anthropic. The erosions are mainly
\end{abstract}

B.goiano.geogr, Goiânia, v. 29, n. 2, p. 127-142, jul./dez, 2009 
located on forms of relief with slope greater than $10 \%$, covered by latosoil and Cambisoils, developed from rocks of the complex Granolithic Anápolis-Itauçu and in the group Araxá in south of Goiás, where the use of the land has no infrastructure appropriate.

Key words: Integrated analysis. Middle physical. Use of the land. Erosion.

\section{Resumen}

En la actualidad, en escala variable, las ciudades brasileñas tienen problemas comunes, derivados de la grandes modificaciones sufridas en las décadas anteriores y se agravó en los últimos años, por la falta de planificación y control del uso de la tierra. En la ciudad de Anápolis-G0, el uso de la tierra, no levó en cuenta la fragilidad del medio físico en el que se insertó, que condiciona a los municipios problemas ambientales, que se reflejan en la incidencia de la erosión lineal, la sedimentación y las inundaciones. La cuenca del Ribeirão Extrema es una de las areas de Anápolis con este tipo de problema ambiental. Delante de eso, el presente estudio investigó la relación entre los condicionates del medio fisico, incluyendo su uso y la ocurrencia de la erosión lineal en esta cuenca. Se fundamenta en el análisis integrado de los componentes de la naturaleza y la sociedad, hizo posible con la ayuda de las tecnologías de los SIG. Los resultados obtenidos muestran que la distribución de los focos de erosión se relaciona tanto a los condicionantes naturales como artificiales. Las erosiones se encuentran principalmente en accidentes geográficos con declive superiores al 10\%, cubierta por Latosuelos y Cambisuelos, desarrollado a partir de rocas del complejo Granulitic Anápolis_Itauçu y del grupo Araxá del Sur de Goiás, donde el uso de la tierra no tiene infraestructura adecuadas.

Palabra claves: Análisis integrado. Medio físico. Uso de la tierra. Erosión.

\section{Introdução}

É de fundamental importância a análise da intervenção humana no ambiente, pois é ela que provoca degradações e desequilíbrios ambientais, sendo de responsabilidade dos usuários dos recursos naturais, a sua preservação e/ou recuperação quando for o caso.

Entre as décadas de trinta e sessenta, o Brasil passou por intensas modificações nas atividades econômicas, que resultou num acelerado processo de urbanização, seguido de uma rápida industrialização e crescimento demográfico com um incremento forte após a década de setenta. Atualmente, em escala variável, as cidades brasileiras apresentam problemas comuns, derivados das intensas modificações sofridas em décadas anteriores e agravados ao longo dos anos, pela falta de planejamento e controle da utilização da terra.

Na cidade de Anápolis-GO, o uso das terras, não levou em consideração as fragilidades do meio físico em que se inseria, condicionando ao município problemas de ordem ambiental, que se refletem na ocorrência de processos erosivos lineares, assoreamentos e inundações. Essa problemática tem instigado à curiosidade de pesquisadores (LACERDA, 2004; LACERDA ET AL. 2004; OLIVEIRA E TEIXEIRA 2004; JESUS 2004; SANTOS 2004; LACERDA 2005; LACERDA ET AL. 2005; LACERDA, TEIXEIRA E OLIVEIRA 
2005; TEIXEIRA 2005). Para Lacerda (2005), em Anápolis os locais propícios à instalação de processos erosivos lineares são: cortes e aterros, realizados nas construções de estradas, caixas de empréstimo, cercas, estradas vicinais, caminhos, trilhas feitas pelo gado e cabeceiras de drenagem. $\mathrm{O}$ alto curso do ribeirão Extrema foi uma das áreas em que Lacerda (2005) mapeou erosões na forma de sulcos, ravinas e voçorocas, condicionadas pela concentração do fluxo superficial nestes locais.

Assim, o presente trabalho investigou a relação entre os condicionantes do meio físico, incluindo a sua utilização e a ocorrência dos processos erosivos lineares na bacia do ribeirão Extrema em Anápolis-GO. Essa bacia localiza-se em área de expansão urbana, no extremo sudeste do município de Anápolis, entre as coordenadas planas N: $8.186 .000 \mathrm{~m}$ e $8.197 .000 \mathrm{~m}$ / E: $718.750 \mathrm{~m}$ e $735.000 \mathrm{~m}$, Meridiano Central: 51ㅇ 00' W Gr (Figura 1). O ribeirão Extrema é afluente pela margem direita do rio das Antas, sendo o afluente, mais importante em território anapolino. A bacia em questão fazse interessante nos estudos do meio físico com vistas a diagnosticar áreas afetadas por processos erosivos lineares, principalmente quando estes estão relacionados ao uso inadequado da terra. Esse quadro é reforçado no estudo em questão, por se tratar de uma área em expansão urbana. Assim, observase que os problemas ambientais aí, decorrem da falta de planejamento das atividades humanas e de estudos detalhados das características do meio físico em questão.

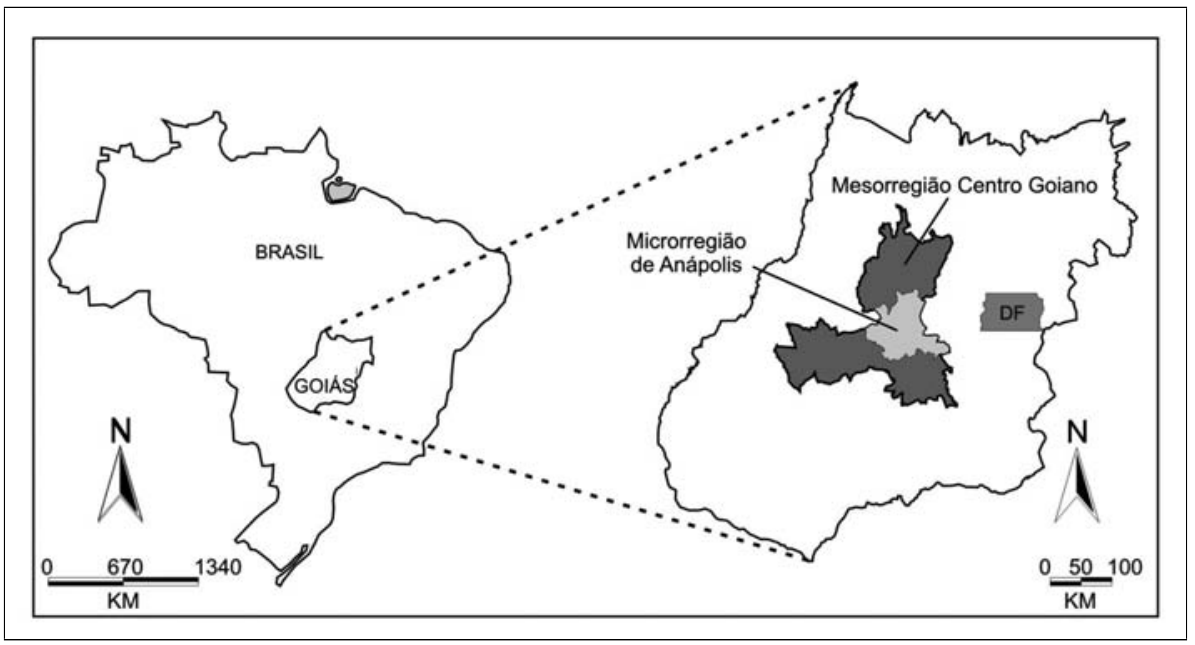




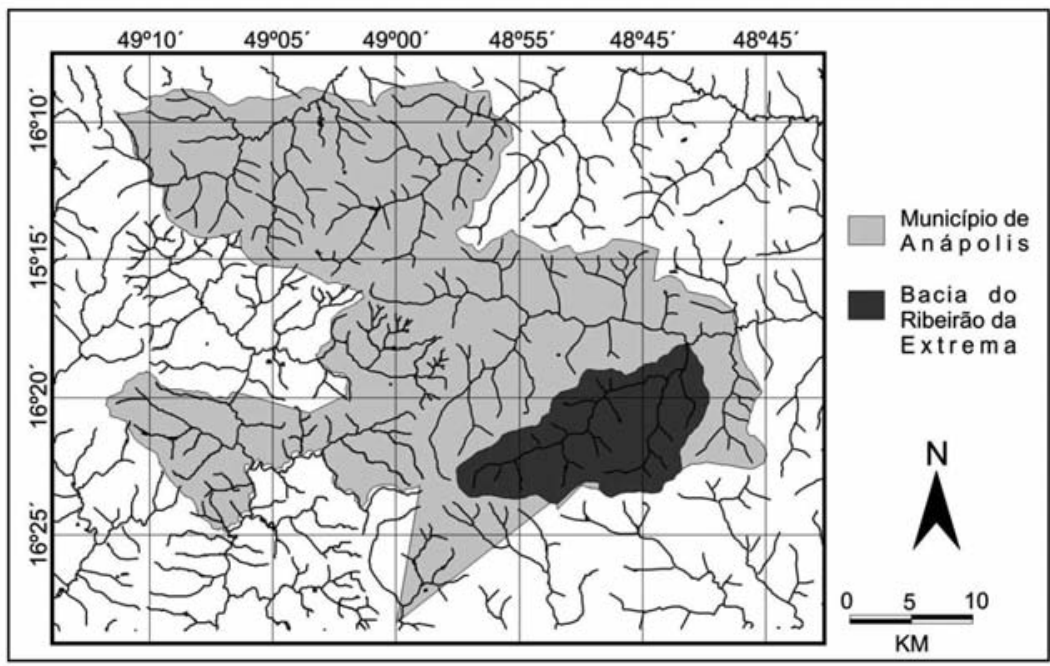

Figura 1: Localização bacia ribeirão Extrema.

\section{Análise integrada e processos erosivos}

Para Orellana (1985, p. 125) [...] "os estudos ambientais procuram compatibilizar o desenvolvimento da economia humana com as restrições impostas pela natureza." Segundo essa autora, o que está em jogo é a gestão dos recursos naturais, com o objetivo de assegurar à sociedade uma melhor qualidade de vida. Para tanto, um estudo ambiental tem que partir de um diagnóstico de problemas, seguido das prioridades envolvidas, visto que a questão chave é a intervenção humana sobre a natureza.

Numa análise ambiental, é necessário prever as alterações impostas pelas atividades antrópicas aos processos do meio físico. As alterações nos processos do meio físico correspondem à alterações no meio ambiente, que, muitas vezes, se traduzem em degradações ambientais. Segundo Fornasari Filho (1992, citado por BITAR, 1995), o meio físico pode ser entendido, como o conjunto do meio ambiente definido pelas interações de componentes bióticos e abióticos, incluindo as modificações decorrentes da ação humana. Os processos do ambiente que decorrem de interações com predominância de componentes abióticos (clima, substrato, relevo e solos), são considerados processos do meio físico (FORNASARI FILHO E BITAR, 1995). 
De acordo com Prandini et al. (1995), os fenômenos do meio físico podem ser classificados como endógenos e exógenos. Os processos exógenos são responsáveis por intensas modificações físicas e químicas das rochas, originando os solos e promovendo a erosão das terras altas e o entulhamento das terras baixas. Os processos exógenos ocorrem naturalmente no meio físico, mas também podem ser induzidos ou alterados por atividades humanas como a mineração, urbanização, agricultura, pecuária e a construção de estradas. A ação antrópica manifesta-se através da movimentação e desestruturação dos materiais pedológicos e geológicos, alteração no escoamento das águas de superfície e subsuperfície, impermeabilização do solo, remoção da cobertura vegetal e introdução de substâncias e elementos químicos nas águas e solos (INFANTI JUNIOR E FORNASARI FILHO, 1998).

Todavia o homem em seu processo civilizatório, ao alterar o meio, de forma direta ou indireta provoca modificações profundas na superfície do planeta, tornando-se um agente muito ativo entre as forças exógenas (PRANDINI ET AL., 1995). Um dos aspectos mais evidentes da ação do homem sobre a superfície da Terra é a modificação do relevo. O homem como agente geomorfológico altera as formas de relevo diretamente através de aterros, escavação, interferência nos canais fluviais, etc. e indiretamente através de ações que aceleram os processos dinâmicos superficiais naturais, como erosão, sedimentação, subsidência, escorregamento, etc (BROWN, 1970).

Assim, o resultado da ação humana na transformação da paisagem apresenta variações relativas (positivas ou negativas, grandes ou pequenas), sendo, portanto considerado impacto ambiental. Conforme esclarece Coelho (2004, p. 24) "os processos de mudanças sociais e ecológicas causados por perturbações no ambiente, podem ser denominados impactos ambientais". Assim, Coelho (2004) propõe uma visão teórica baseada nas reqüe de Marx e Engels, que na tentativa de superar o reducionismo referente à problemática ambiental, analisa-a além da questão natural, inserindo-se a questão social e política. Segundo Guerra e Marçal (2006), é possível destacar a erosão como um dos principais impactos ambientais deflagrados pelo uso da terra.

Para Oliveira (1998) a erosão consiste na ação combinada de um conjunto de fatores, que provocam a desagregação e o transporte de partículas do solo, ou fragmentos e partículas de rochas, sobre a superfície terrestre. A erosão hídrica linear é causada pela concentração das linhas de fluxo das águas de escoamento superficial, resultando em incisões na superfície do terreno, na forma de sulcos, ravinas e voçorocas (CUNHA, 1991; SALOMÃO E IWASA, 1995; OLIVEIRA, 1998; INFANTI JUNIOR E FORNASARI FILHO, 1998). 
São denominados sulcos, pequenas incisões na superfície, com profundidade inferior a 0,5 m. Desenvolvem-se em áreas, nas quais a erosão laminar é mais intensa, podendo ser eliminados por operações normais de manejo do solo. Ravinas são incisões mais profundas do que os sulcos, diferenciando-se dos sulcos por não serem obliteradas pelas operações normais de preparo do solo. Ocorrem quando a água do escoamento superficial escava o solo, atingindo seus horizontes inferiores e, em seguida, a rocha. Nas ravinas podem ocorrer, também, movimentos de massa devido ao abatimento de seus taludes. Voçorocas são as incisões que atingiram o lençol freático. Devem-se à ação combinada das águas do escoamento superficial e subsuperficial, desenvolvendo processos como o pipping (erosão interna), movimentos de massa, solapamentos, subsidências e colapsos (IPT, 1990; ALMEIDA FILHO E RIDENTE JUNIOR, 2001; SALOMÃO, 1999). As voçorocas podem estar conectadas aos cursos d'água, quando instaladas nesses, ou serem voçorocas desconectadas, quando são formadas pelo aprofundamento de ravinas até o nível freático (OLIVEIRA, 1999).

O estudo ora apresentado fundamenta-se na análise integrada dos componentes da natureza e da sociedade, viabilizada com o auxílio das tecnologias de geoprocessamento. Essa análise partiu do levantamento de material bibliográfico, compilação de documentação cartográfica existente, dados secundários obtidos junto a órgãos governamentais e dados primários obtidos em trabalho de campo.

A documentação cartográfica compilada e/ou elaborada compreendeu os seguintes mapas: planialtimétrico, hipsométrico, de declividades, de curvaturas, de curvaturas planas e de curvaturas do perfil, geológico, de solos, de compartimentos do relevo, de uso da terra e de ocorrências erosivas. Esse trabalho apresenta apenas os mapas de uso da terra e compartimentos do relevo associado a processos erosivos, os outros mapas podem ser consultados em Teixeira (2008).

A escala de trabalho adotada é de 1:50.000, que corresponde a maior escala da carta topográfica disponível para a área de estudo. Salienta-se que os trabalhos de campo foram fundamentais para melhor detalhar as informações cartografadas.

Assim, a base cartográfica para a análise integrada foi a carta planialtimétrica, folha SE.22-X-B-II-3 (DSGB, 1974), complementada com a imagem Cbers2 (Satélite Sino Brasileiro de Recursos Terrestres), sensor CCD (Câmera Imageadora de Alta Resolução), bandas 4, 3 e 2 das cenas 158/118 (08/08/2007), (INPE, 2007), que serviu para o detalhamento da rede de drenagem. 
B.goiano.geogr, Goiânia, v. 29, n. 2, p. 127-142, 2009

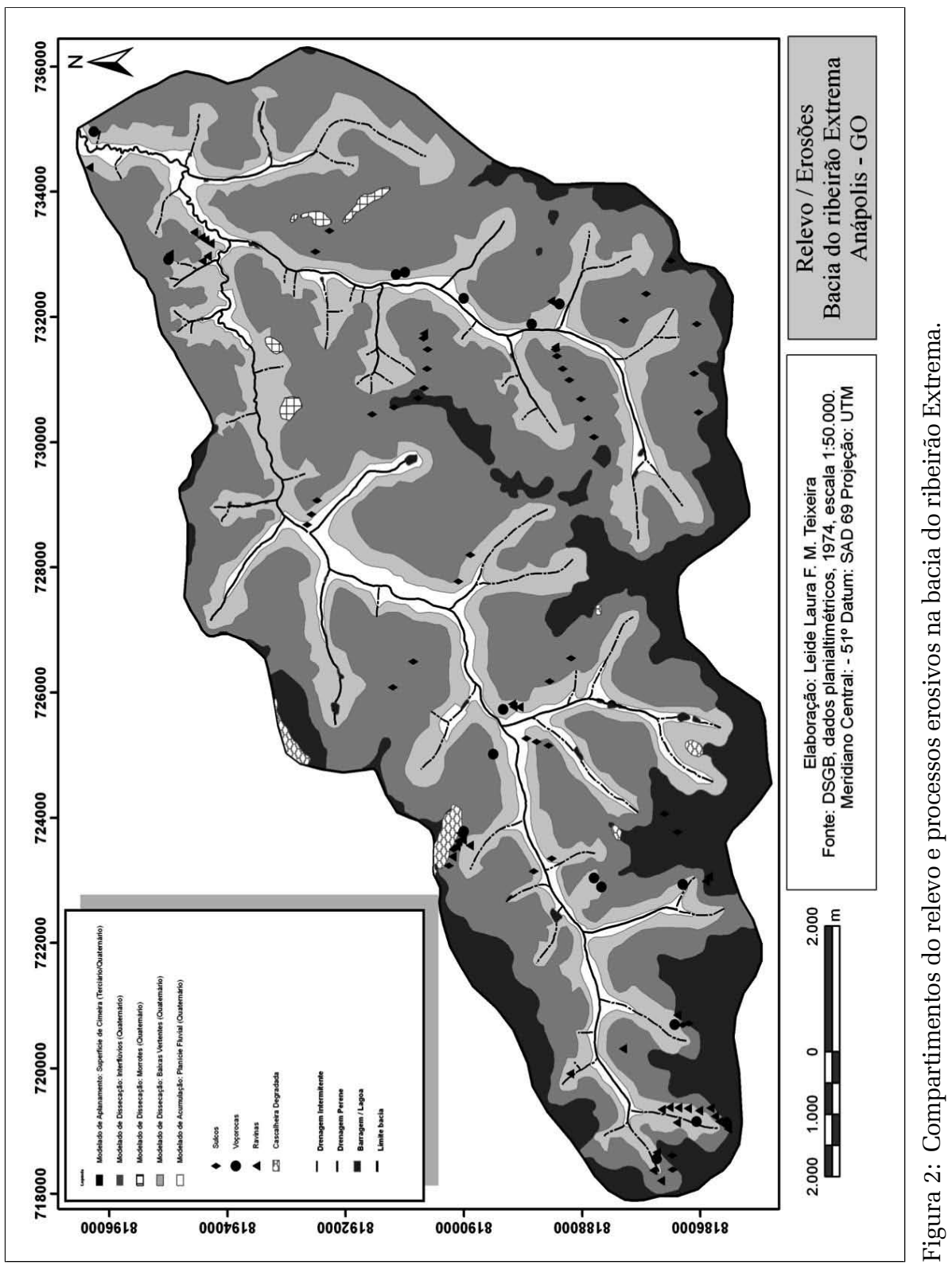




\section{Análise integrada do meio físico da bacia do ribeirão Extrema}

A análise integrada, ora apresentada, foi desenvolvida a partir do cruzamento dos elementos do meio físico, incluindo o uso da terra, com a ocorrência de processos erosivos lineares na área de estudo (Figuras 3 e 4). Logo, essa análise busca discernir a relação entre a ocorrência desses processos erosivos e as características dos elementos naturais e antrópicos que compõem a bacia hidrográfica em questão. Os compartimentos do relevo, relacionados às características do clima, geologia, solos, e uso da terra permitiram fazer considerações a respeito da capacidade de uso das terras, mensurar classes de suscetibilidade à erosão, bem como fazer analogias quanto aos aspectos legais de utilização da terra.

O compartimento Superfície de Cimeira compreende uma área correspondente a $15 \%$ da bacia (Figura 4), é caracterizado por áreas com as maiores altitudes e menores declividades, que, em geral, constituem o divisor de águas da bacia sustentado por Cobertura Detrito-Laterítica, onde predominam Plintossolos Pétricos Concrecionários, sendo o cerrado a vegetação original correspondente.

De acordo com a capacidade de uso agrícola das terras, esse compartimento possui terras melhor adaptadas para pastagem, que também podem ser utilizadas para reflorestamentos. Sua limitação é referente ao solo que se apresenta muito pedregoso, dificultando o enraizamento das plantas em profundidade e ainda possui baixa saturação por bases, que pode ser corrigida (LEPSCH ET AL., 1983). Na área de estudo essas terras são destinadas, principalmente, ao uso urbano, abrangendo também atividades de mineração na forma de cascalheiras, além de atividades pecuárias. Nesse compartimento pouco restou da vegetação original de cerrado, os poucos remanescentes que ainda existem são restritos a morros residuais da superfície de cimeira, bem como a algumas de suas bordas e/ou são áreas de reserva legal que por vezes também são utilizadas como pasto. 
B.goiano.geogr, Goiânia, v. 29, n. 2, p. 127-142, 2009 Artigo

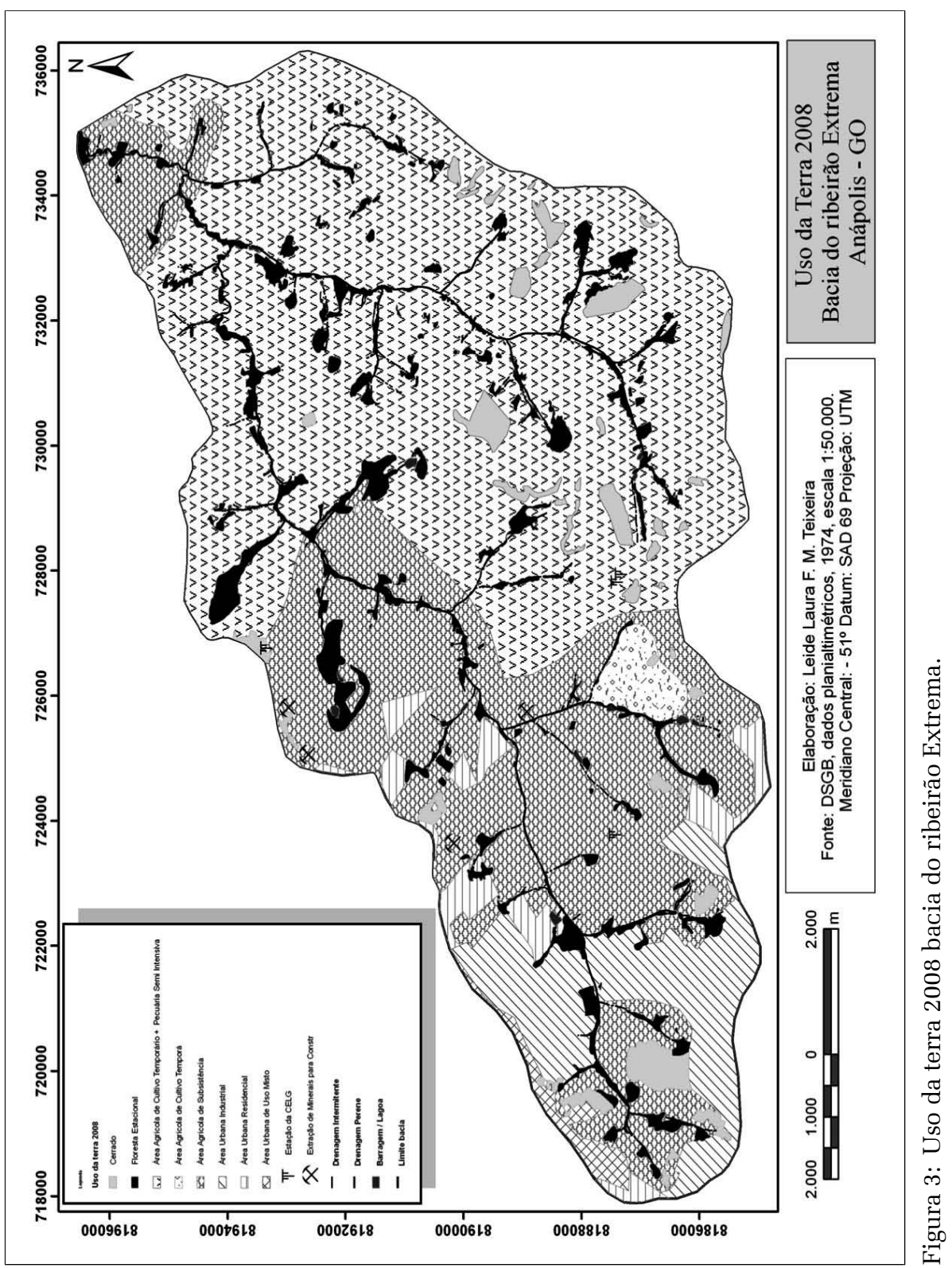




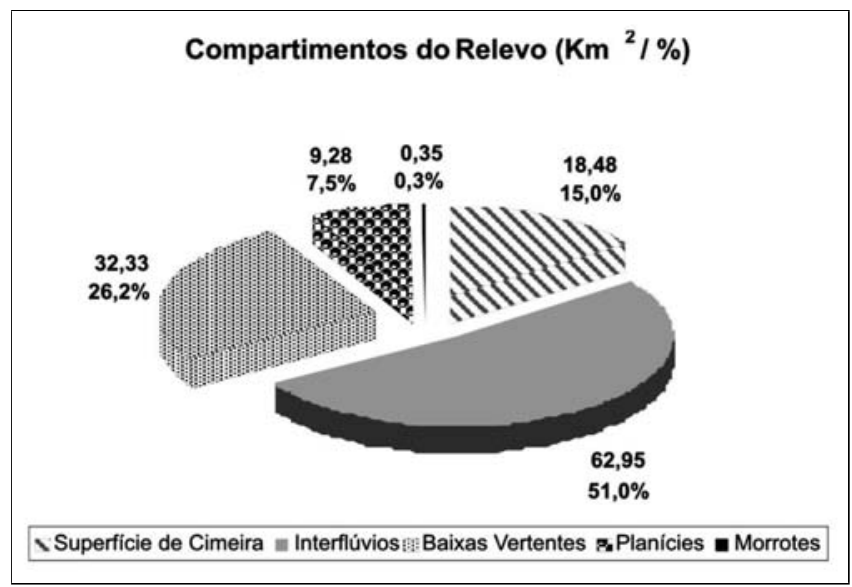

Figura 4: Gráfico Área dos Compartimentos de Relevo.

Em casos restritos como nas bordas desse compartimento e quando esse se apresenta de forma isolada como em morros convexos, a declividade também é um limitante de uso tanto em áreas rurais, cuja declividade recomendada para o uso intensivo é de até 12\% (LEPSCH ET AL., 1983), como em áreas urbanas, onde a declividade máxima permitida para ocupação é de 30\% (BRASIL, 1979). Além disso, o Código Florestal Brasileiro considera como áreas de preservação permanente topos de morros e bordas de chapadas, no caso das bordas devem ser preservados no mínimo $100 \mathrm{~m} \mathrm{em}$ projeção horizontal, contados a partir da linha de ruptura de declive que delimita a escarpa (BRASIL, 1998).

Na bacia do ribeirão Extrema, as bordas do compartimento de Cimeira, em geral, não são preservadas. Destinadas à urbanização e mineração, tornam-se muito suscetíveis a erosões. Em suas condições naturais esse compartimento seria caracterizado como não suscetível a erosão. Embora nele tenham sido mapeados processos erosivos, esses estão relacionados ao uso inadequado da terra e à não observância da legislação vigente, em áreas de extração de materiais para construção civil, onde não se implantou a técnica apropriada e em estradas geralmente longas, que seguem o sentido de aumento do declive e não contam com infraestrutura adequada, como cobertura asfáltica e um sistema de captação e dissipação das águas pluviais. Fora as restrições ora citadas, o compartimento de cimeira constitui-se num sólido alicerce para edificações, portanto adequado à urbanização. 
O compartimento dos interflúvios, com 51\% de área, é caracterizado por apresentar altitudes altas e médias e declividades inferiores a 9\%, constituindo em geral interflúvios amplos e médios. Esses interflúvios foram esculpidos sobre rochas do Grupo Araxá Sul de Goiás e em menor proporção rochas do Complexo Granulítico Anápolis-Itauçu, que deram origem a solos espessos como Latossolo Vermelho e Vermelho Amarelo, recobertos por cerrado. De acordo com a capacidade de uso, essas terras são adaptadas para qualquer tipo de uso agrícola, sendo mais bem utilizadas na agricultura, pois possuem relevo, predominantemente, plano favorecendo seu uso com variados tipos de cultura e também à mecanização. Possui limitação referente ao solo, que por ser distrófico apresenta baixo índice de saturação por bases, o que também pode ser corrigido. (LEPSCH ET AL., 1983).

Nesse último compartimento descrito predomina o uso agrícola das terras na forma de agricultura de subsistência, agricultura com cultivo temporário e pecuária. Também se destina à urbanização, que se encontra em processo de expansão sobre a área de estudo. O intenso uso dessas terras praticamente acabou com a vegetação natural, tendo restado alguns remanescentes. A maior área recoberta por remanescentes de cerrado na bacia do ribeirão Extrema é a área de proteção ambiental (APA) da UEG. Outras áreas permanecem como reserva legal, porém, o estado de conservação desses remanescentes é precário, que também servem à população como pasto e depósito de lixo.

As baixas declividades e os solos espessos, cuja estrutura pequena granular fortemente desenvolvida os tornam permeáveis, conferem a esse compartimento baixa suscetibilidade à erosão. Essa suscetibilidade se deve à estrutura desses solos, cuja coesão entre as partículas é muito baixa, o que facilita o arraste das mesmas e ao grande comprimento de rampa, que condiciona a aceleração do fluxo. Assim a suscetibilidade desse compartimento é potencializada quando submetido à ação de fluxos d'água concentrado. Essa é uma situação reqüente na área de estudo, onde a construção de estradas no sentido de aumento do declive, sobre longas vertentes sem pavimentação asfáltica e sistema de drenagem do escoamento superficial, ou até mesmo a construção de cercas, valetas e pisoteio excessivo de gado, condicionam a ocorrência de processos erosivos na forma de sulcos, ravinas e voçorocas.

O compartimento dos morrotes com 0 a 3\% de área, altas declividades e morfologia convexa, esculpidos sobre quartzitos do Grupo Araxá Sul de Goiás e silexitos do Complexo Granulítico Anápolis-Itauçu, consiste em 
terrenos onde a resistência das rochas ao intemperismo condicionou a formação de Neos.solo Litólico. As terras desse compartimento são impróprias para a utilização agrícola e urbana. No primeiro caso, as limitações são referentes aos solos muito rasos e pedregosos, que impossibilitam a mecanização e o desenvolvimento de plantas cultivadas. Nos dois casos a declividade também é um limitante, sendo que são superiores a $30 \%$. Diante dessas condições essas terras são protegidas pela legislação, devendo ser destinas a preservação permanente. Na área de estudo alguns desses morrotes encontram-se desprovidos de cobertura vegetal original. Esse compartimento não é suscetível à erosão, visto que é composto por um horizonte A pouco espesso, sobreposto em geral a rocha sã. Essas rochas com igual resistência a erosão propiciaram uma morfologia convexa ao relevo, constituindo assim formas distribuidoras d'água.

As baixas vertentes, ocupam uma área de $26,2 \%$ da bacia do ribeirão Extrema. É um compartimento onde predominam baixas altitudes e altas declividades, constituindo diversas formas de vertentes, incluindo cabeceiras de drenagem, esculpidas em geral sobre gnaisses e quartzitos do Complexo Granulítico Anápolis-Itauçu e em alguns casos restritos, sobre micaxistos e quartzitos do Grupo Araxá Sul de Goiás. Essas rochas condicionaram a formação de Latossolo Vermelho Amarelo, Latossolo Vermelho, Cambissolo, Neossolo Litólico e Gleissolo recobertos, em geral, por Floresta Estacional. De acordo com a capacidade de uso essas terras são adaptadas para pastagens e reflorestamentos, são impróprias para culturas anuais, porém, cultiváveis apenas em casos especiais com algumas espécies permanentes protetoras do solo. Com relação ao uso agrícola, a principal limitação é quanto à declividade, já que nesse compartimento predominam declives maiores que $14 \%$, enquanto recomenda-se o uso de áreas com até $12 \%$ de declividade. Os Cambissolos, Neossolos Litólicos e Gleissolos também se configuram como limitantes ao uso agrícola. Nos primeiros a limitação é devida, principalmente, a pouca profundidade e/ou pedregosidade, que podem dificultar a mecanização, possuem ainda baixa saturação por bases, que pode ser corrigida. No caso dos Gleissolos a limitação deve-se principalmente ao excesso d'água (LEPSCH ET AL., 1983).

As altas declividades, as formas côncavas e côncavo-convexas e a pouca espessura dos solos nesse compartimento supracitado lhe conferem alta suscetibilidade à erosão. Logo, os condicionantes naturais sob o mau uso da terra, onde faltam infraestruturas adequadas à captação e dissipação das águas superficiais aumentam o potencial de erosão dessas terras. A 
utilização das terras nesse compartimento comporta, principalmente, o uso agrícola de subsistência, algumas áreas de cultivo temporário e algumas áreas recentemente urbanizadas. Em geral, esse compartimento é o último a passar pelo processo de urbanização, no entanto, é afetado pelo escoamento superficial concentrado vindo das áreas urbanizadas de montante. Assim, o compartimento das Baixas Vertentes é palco de vários e intensos processos erosivos, desencadeados por condicionantes naturais e antrópicos de processos do meio físico. Alguns dos novos loteamentos da bacia do ribeirão Extrema levaram à urbanização de nascentes e cabeceiras de drenagem, áreas definidas pelo Código Florestal Brasileiro como sendo de preservação permanente (APP). A esse respeito, a vegetação que ocorre ao longo dos cursos dos rios não foi preservada, como orienta o Código Florestal Brasileiro. Essa situação também contribui para a ocorrência de processos erosivos.

O compartimento das planícies fluviais, com 7,5\% de área, compreende as menores altitudes e declividades, sobrepostas, em sua maioria, por Depósitos Aluvionares, onde a baixa profundidade do lençol freático condicionou a formação de Gleissolos. A vegetação original corresponde à Floresta Estacional. De acordo com a capacidade de uso, são terras impróprias para a utilização agrícola, com limitações principalmente devidas ao excesso de água, localizando-se muito próximas aos cursos d'água, possuindo risco de inundação (LEPSCH ET AL., 1983). Do ponto de vista da legislação, são áreas destinadas a preservação permanente. A suscetibilidade a erosão é nula, porém, essas áreas são afetadas pelos sedimentos oriundos dos processos erosivos lineares de montante.

\section{Considerações finais}

A análise integrada ora apresentada mostrou-se adequada ao diagnóstico de processos erosivos, pois permitiu identificar cinco compartimentos de relevo, os quais possuem características homogêneas no que diz respeito à interação entre o substrato geológico, declividades, altitudes, curvatura das vertentes, solos e ocorrências erosivas.

Dentre os compartimentos de relevo delimitados, apenas as Planícies Fluviais e os Morrotes não apresentam focos erosivos, porém, as primeiras em função da sua proximidade aos cursos d'água são consideradas áreas de preservação permanente, bem como os Morrotes devido suas altas declividades. Contudo observou-se a retirada da vegetação de algumas dessas 
áreas e o uso das Planícies Fluviais num raio inferior a $30 \mathrm{~m}$ para o parcelamento urbano e uso agrícola.

Em todos os outros compartimentos de relevo foram registrados processos erosivos. O compartimento mais afetado por erosões são as Baixas Vertentes, naturalmente suscetíveis à instalação desses processos e vítimas do escoamento superficial concentrado, tanto em áreas urbanas como agrícolas. Nesse compartimento foram registradas quatro áreas com ocorrência de sulcos, dezoito ravinas e quatorze voçorocas.

Em segundo lugar estão os Interflúvios menos suscetíveis a erosões, com estradas construídas em longas vertentes, no sentido de aumento do declive, sem pavimentação asfáltica e sistema de drenagem do escoamento superficial, ou até mesmo a construção de cercas, valetas e pisoteio excessivo de gado. Esses fatos condicionaram a ocorrência de sete áreas afetadas por sulcos, sendo que em duas dessas, os processos erosivos iniciaram-se na Superfície de Cimeira, quatorze ravinas estando três localizadas na transição entre esse compartimento e o das Baixas Vertentes e três voçorocas sendo que apenas uma dessas não se iniciou na transição entre os compartimentos de Cimeira ou Baixas Vertentes.

A Superfície de Cimeira naturalmente não suscetível a ocorrências erosivas, também tem sido vítima do escoamento superficial concentrado, exclusivamente em estradas que não contam com sistema de drenagem e cascalheiras desprovidas de vegetação natural. Nas estradas foram registradas quatro áreas com ocorrência de sulcos e três ravinas. Cinco cascalheiras foram mapeadas com ocorrência de processos erosivos intensos.

Assim, conclui-se que bacia do ribeirão Extrema apresenta sérios problemas relacionados aos processos erosivos lineares, cuja gênese está associada ao uso da terra sem a infraestrutura necessária e sem a observação dos condicionantes naturais do meio físico. Nota-se que o sistema de arruamento, a construção de valetas, cercas e o pisoteio excessivo do gado alteram as condições naturais de infiltração e escoamento superficial, condicionando a concentração do fluxo em linhas preferenciais onde se desenvolvem os processos erosivos. Soma-se a esse fato, a retirada da cobertura vegetação natural e o uso urbano e rural em áreas impróprias, desrespeitando o aparato legal. Logo, tem-se o cenário ideal a deflagração dos processos erosivos.

O diagnóstico apresentado pode servir como referencial para trabalhos futuros, como fonte inicial para um planejamento e manejo adequado das formas de uso da terra e no controle preventivo e corretivo dos processos erosivos em uma bacia hidrográfica. Salienta-se a necessidade de 
se desenvolver estudos com maior detalhe, para melhor compreensão dos mecanismos que atuam no processo de gênese e evolução das erosões.

\section{Referências}

ALMEIDA FILHO, G. S. de; RIDENTE JÚNIOR, J. L. Erosão: Diagnóstico, Prognóstico e Formas de Controle. In: Simpósio Nacional de Controle de Erosão, VII, 2001, Goiânia. Minicurso. Goiânia: ABGE, 2001, 84p.

BITAR, O. Y. Perspectivas da geologia de engenharia e meio ambiente. In: BITAR, O. Y. (Org.) Curso de Geologia Aplicada ao Meio Ambiente. São Paulo: ABGE/IPT, 1995, p. 243-247.

BRASIL, Lei Federal n ${ }^{\circ}$ 6.766, de 19 de dezembro de 1979. Dispõe sobre o parcelamento do solo urbano. Diário Oficial da República Federativa do Brasil. Brasília, 20 dezembro de 1979.

BROWN, E. H. O homem modela a terra. Boletim Geográfico. Rio de Janeiro, ano 30, v. 222, p. 3-18, maio/junho, 1970.

COELHO, M. C. N. Impactos Ambientais em Áreas Urbanas-Teorias Conceitos e Métodos de Pesquisa. In: GUERRA, A. J. T.; CUNHA, S. B. de (Org.). Impactos Ambientais Urbanos no Brasil. Rio de Janeiro: Bertrand Brasil, 2004, p. 19-43.

CUNHA, M. A. Ocupação de encostas. São Paulo: IPT, 1991.

FORNASARI, F. N.; BITAR, O. Y. O meio físico em estudo de impacto ambiental-EIAS. In: BITAR, O. Y. (Org.) Curso de Geologia Aplicada ao Meio Ambiente. São Paulo: ABGE/IPT, 1995. p. 151-163.

INFANTI JUNIOR, N.; FORNASARI FILHO, N. Processos de Dinâmica Superficial. In: OLIVEIRA, A. M. S.; BRITO, S. N. A. de (Org.). Geologia de Engenharia. São Paulo: ABGE, 1998, p. 131-152.

INPE. INSTITUTO BRASILEIRO DE PESQUISAS ESPACIAIS. Imagens Orbitais Satélite Sino Brasileiro de Recursos Terrestres. Disponível em: <http://www.dgi.inpe.br/CDSR/>. Acesso em: 13/05/2007.

IPT. INSTITUTO DE PESQUISAS TECNOLÓGICAS. Departamento de Águas e Energia Elétrica. Controle de Erosão. São Paulo, 1990.

JESUS, A. S. de. Geomorfologia antrópica e riscos geomorfológicos e hidrológicos na porção centro-leste de Anápolis (GO). In: AGB, 6. Congresso Brasileiro de Geógrafos. Goiânia: Anais, disco compacto, 2004, 12p.

LACERDA, H. Riscos geológicos e formas de relevo em Anápolis (GO). $42^{\circ}$ Congresso Brasileiro de Geologia, Araxá: Anais, disco compacto, 2004, 12p.

LACERDA, H. et. al. Uso da Terra, Formas de Relevo e Riscos Geológicos na Área Central de Anápolis (GO). Plurais, Anápolis. 2004.

LACERDA, H. Mapeamento geomorfológico como subsídio ao controle preventivo da erosão em Anápolis-GO. In: 11 congresso brasileiro de geologia de engenharia ambiental. ABGE 13 a 16-11-2005, Florianópolis, SC. p. 679 a 692. 
LACERDA, H. et al. Riscos geológicos e uso da terra em Anápolis (GO). Educação e Mudança, Anápolis, 2005.

LACERDA, H.; TEIXEIRA, L. L. F. M.; OLIVEIRA, S. N. Diagnóstico geológico-geomorfológico da erosão acelerada e do assoreamento na bacia do alto curso do Rio das Antas em Anápolis (GO). Anais II Simpósio Sobre Solos Tropicais e Processos erosivos lineares no Centro-Oeste, 2005.

LEPSCH, I. F. et. al. Manual para levantamento utilitário do meio físico e classificação de terras nosistema de capacidade de uso: $4^{\mathrm{a}}$ aproximação. Campinas: SBCS, 1983.

OLIVEIRA, L. M. de. Guia de prevenção de acidentes geológicos urbanos. Curitiba: MINEROPAR, 1998. $52 \mathrm{p}$.

ORELLANA, M. M. P. Metodologia Integrada no Estudo do Meio Ambiente. Geografia. UFMG, 1985.

PRANDINI, F. L. et. al. Cartografia geotécnica nos planos diretores regionais e municipais. In: BITAR, O. Y. (Org.) Curso de Geologia Aplicada ao Meio Ambiente. São Paulo: ABGE/IPT, 1995. p. 187-196.

SALOMÃO, F. X. de T. Controle e Prevenção dos Processos erosivos lineares. In: GUERRA, A. J.T.; SILVA, A. S.; BOTELHO, R. G. M. (Orgs.) Erosão e Conservação dos Solos: conceitos, temas e aplicações. Rio de Janeiro: Bertrand Brasil, 1999, 340 p.

SANTOS, L. R. dos. Compartimentação do relevo na porção noroeste de Anápolis (GO). In: AGB, 6. Congresso Brasileiro de Geógrafos, Goiânia. Anais, disco compacto, 2004, 10p.

TEIXEIRA, L. L. F. M. Análise Integrada do Meio Físico como Subsídio ao Diagnóstico de Processos Erosivos na Bacia do Ribeirão Extrema em Anápolis (GO). Dissertação de Mestrado. IESA-UFG, Goiânia, 2008.

Leide Laura F. M. Teixeira - Mestranda do programa de Pesquisa e Pós-Graduação do Instituto de Estudos Sócioambientais da Universidade Federal de Goiás.

Patrícia de Araújo Romão - Professora do Instituto de Estudos Sócio-Ambientais da Universidade Federal de Goiás. 